\title{
PROGRAMA NACIONAL DE CRÉDITO FUNDIÁRIO (PNCF) EM SERGIPE: AVANÇOS, LIMITES E CONTRADIÇÕES ${ }^{1}$ \\ NATIONAL FUNDIARY CREDIT PROGRAM (PNCF) IN SERGIPE: ADVANCES, LIMITS AND CONTRADICTIONS \\ PROGRAMA NACIONAL DE CRÉDITO FUNDIARIO (PNCF) EN SERGIPE:
} AVANCES, LÍMITES Y CONTRADICCIONES

\author{
José Eloízio da Costa ${ }^{2}$ \\ https://orcid.org/0000-0002-3777-5403 \\ Fabiana dos Santos Pinheiro ${ }^{3}$ \\ https://orcid.org/0000-0002-9508-6139 \\ Daniela Santos Feitoza ${ }^{4}$ \\ https://orcid.org/0000-0003-1330-5463
}

Submissão: 30/11/2020 / Aceito: 02/03/2021 / Publicado: 31/01/2021.

\begin{abstract}
Resumo
A concentração fundiária é um fato marcante na história do Brasil. Diante disso, em 2003, o governo federal criou um importante instrumento de política pública para viabilizar a compra de terras e imóveis que não podem ser desapropriados: o Programa Nacional de Crédito Fundiário (PNCF). Este programa tem sido relevante para o melhoramento das condições socioeconômicas de pequenos produtores, especialmente da região Nordeste. Por sua vez, o caso de Sergipe é emblemático, pois do ponto de vista nacional o PNCF ainda é incipiente, todavia alguns avanços e melhorias precisam ser enfatizados. Nesse aspecto, o presente artigo busca analisar os principais efeitos e contradições gerados a partir do PNCF no estado de Sergipe. Tendo como caminhos metodológicos o levantamento bibliográfico, coleta de dados secundários, trabalho de campo e análise crítica dessas informações. Para tanto, a superação de demandas históricas e das complexidades do mundo rural passa eminentemente por reestruturações qualitativas das políticas públicas de modo a ampliar sua integração, bem como seu alcance econômico e espacial. Além disso, é preciso considerar o fomento financeiro desses programas governamentais na contramão das medidas de austeridade, mediante criação e
\end{abstract}

\footnotetext{
1 Este trabalho foi resultado do relatório parcial de pesquisa de Iniciação Científica (IC), com apoio financeiro do Conselho Nacional de Desenvolvimento Científico e Tecnológico (CNPQ), realizado durante o primeiro semestre de 2019.

2 Pós-Doutor em Geografia. Professor Titular do Departamento de Geografia e Professor Permanente do Programa de Pós-Graduação em Geografia da Universidade Federal de Sergipe (UFS). E-mail: eloizio.npgeo@gmail.com

${ }^{3}$ Mestranda em Geografia. Aluna do Programa de Pós-Graduação em Geografia da Universidade Federal de Sergipe (UFS). E-mail: fabiana-pinheiro16@hotmail.com

${ }^{4}$ Mestre em Geografia pelo Programa de Pós-Graduação em Geografia da Universidade Federal de Sergipe (UFS). E-mail: danielafeitoza22@gmail.com
} 
desenvolvimento de um planejamento estratégico, que pondere especialmente as condições socioeconômicas das famílias rurais pobres.

Palavras-chave: Desenvolvimento Rural. Justiça Fundiária. Crédito Rural. Contradições.

\section{Abstract}

Land concentration is a remarkable fact in the history of Brazil. In view of this, in 2003, the federal government created an important public policy instrument to enable the purchase of land and properties that cannot be expropriated: the National Land Credit Program (PNCF). This program has been relevant for improving the socioeconomic conditions of small producers, especially in the Northeast region. In turn, the case of Sergipe is emblematic, since from the national point of view the PNCF is still incipient, however some advances and improvements need to be emphasized. In this regard, this article seeks to analyze the main effects and contradictions generated from the PNCF in the state of Sergipe. The bibliographic survey, secondary data collection, fieldwork and critical analysis of this information are used as methodological paths. To this end, overcoming historical demands and the complexities of the rural world goes through qualitative restructuring of public policies in order to expand their integration, as well as their economic and spatial reach. In addition, it is necessary to consider the financial promotion of these government programs against the austerity measures, through the creation and development of a strategic plan, which especially considers the socioeconomic conditions of poor rural families.

Keywords: Rural Development. Land Justice. Rural Credit. Contradictions.

\section{Resumen}

La concentración de la tierra es un hecho notable en la historia de Brasil. Ante esto, en 2003, el gobierno federal creó un importante instrumento de política pública para posibilitar la compra de terrenos y propiedades que no pueden ser expropiadas: el Programa Nacional de Crédito Territorial (PNCF). Este programa ha sido relevante para mejorar las condiciones socioeconómicas de los pequeños productores, especialmente en la región Nordeste. A su vez, el caso de Sergipe es emblemático, ya que desde el punto de vista nacional el PNCF aún es incipiente, sin embargo es necesario destacar algunos avances y mejoras. Al respecto, este artículo busca analizar los principales efectos y contradicciones generados desde el PNCF en el estado de Sergipe. El relevamiento bibliográfico, la recolección de datos secundarios, el trabajo de campo y el análisis crítico de esta información se utilizan como vías metodológicas. Para ello, la superación de las demandas históricas y las complejidades del mundo rural pasa por una reestructuración cualitativa de las políticas públicas con el fin de ampliar su integración, así como su alcance económico y espacial. Además, es necesario considerar la promoción financiera de estos programas gubernamentales frente a las medidas de austeridad, a través de la creación y desarrollo de un plan estratégico, que considere especialmente las condiciones socioeconómicas de las familias rurales pobres.

Palabras chave: Desarrollo Rural. Justicia Territorial. Crédito Rural. Contradicciones. 


\section{INTRODUÇÃO}

Criado em 2003, o Programa Nacional de Crédito Fundiário (PNCF), é uma ação intermediária da Reforma Agrária, com o intuito de viabilizar terras ou reestruturar propriedades rurais, através do custeio público que financia essas propriedades a longo prazo. Apesar de precário e contraditório, tal política pública tem viabilizado melhorias reais nas condições socioeconômicas das famílias rurais, especialmente do Nordeste. Nessa perspectiva, para Abramovay (2004) “o acesso ao crédito, pelas famílias de menor renda, não podem ser encaradas simplesmente como meros negócios de dependência financeira, mas sim como condições reais de transformações no âmbito de realidades desiguais historicamente construídas".

Para tanto, é importante indagar sobre em que medida o programa tem fomentado a reprodução social dos pequenos produtores rurais? Portanto, o objetivo geral do presente artigo é analisar os principais efeitos e as contradições geradas a partir do PNCF no estado de Sergipe. Enquanto que os objetivos específicos foram classificados em: a) Compreender a evolução e os desdobramentos da desigualdade fundiária no Brasil até a criação do PNCF; b) Caracterizar o PNCF e seu alcance socioeconômico no Nordeste; c) Discutir como o PNCF, dentro dos seus limites e possibilidades, infere na reprodução das famílias rurais pobres de Sergipe.

Sendo assim, para atender a complexidade desta investigação, adotou-se o método dialético e empírico-analítico. Por sua vez, baseado nas contribuições de Marconi e Lakatos (2003), os procedimentos metodológicos utilizados para alcançar os objetivos elencados foram: levantamento bibliográfico e discussão de textos; coleta de dados secundários (Ministério da Agricultura, Secretaria de Agricultura de Sergipe, PRONESE, Governo de Sergipe, etc.) e sistematização das informações; trabalho de campo e análise crítica da realidade estudada. Com isso, realizou-se o cruzamento dessas informações, garantindo a sistematização das ideias em conformidade com as reflexões teóricas contidas neste trabalho.

Destarte, a estruturação dos dados (tabelas, gráficos, etc.) foi realizada nos programas Word e Excel, via Windows (2010), já o mapa temático teve sua elaboração no software QGis. Enquanto que a pesquisa empírica foi realizada no dia 03 de fevereiro de 2021, na cidade de Lagarto/SE (maior beneficiária do PNCF em Sergipe no ano de 2019). 
Por esse motivo, essa foi escolhida como base de investigação in loco. Onde, no turno da manhã realizou-se uma visita ao Sindicato de Trabalhadores Rurais de Lagarto (SINTRAF) e logo mais (turno da tarde) ao estabelecimento Fazendinha (adquirido pelo programa), localizado no povoado Jenipapo desse mesmo município, para dialogar com pequenos produtores rurais e também beneficiários locais.

Nesses termos, o presente trabalho foi subdivido em cinco seções: a primeira introdutória, que explica e discute parcialmente a temática abordada, seus objetivos e a metodologia adotada; a segunda destinou-se a contextualizar os motivos que estruturaram a desigualdade fundiária no país, o que justifica a criação do PNCF; a parte subsequente foi proposta para expor as principais características do programa bem como seu funcionamento e seu alcance socioeconômico para o desenvolvimento do mundo rural da região Nordeste; a quarta parte enfatiza as condições do PNCF em Sergipe dando destaque aos impactos para a reprodução dos pequenos produtores rurais; e, finalmente, a última parte expõe as considerações finais em conformidade com os questionamentos de pesquisa. Consequentemente, a trajetória da questão agrária no país foi posta em destaque para entender seus reflexos no estado de Sergipe.

Contudo, esse trabalho justifica-se pela necessidade de conhecer e compreender como o PNCF, dentro dos seus limites e contradições, tem contribuído para garantir a reprodução socioeconômicas de inúmeras famílias rurais. Enfatizando ainda a importância das políticas públicas e do apoio institucional para o desenvolvimento rural brasileiro, tendo em vista o atual contexto neoliberal. Sendo assim, espera-se que este breve ensaio possa auxiliar e nortear demais discussões acadêmicas sobre a complexidade que gira em torno do crédito rural, da desigualdade fundiária e da pequena produção familiar no espaço sergipano.

\section{PNCF, UMA RESPOSTA INSTITUCIONAL A CRÔNICA SITUAÇÃO FUNDIÁRIA BRASILEIRA}

O Brasil é um dos países com maiores índices de concentração fundiária no mundo e isso reflete nas demandas históricas pelo acesso a terra. Nesse aspecto, Prado Junior (1987, p. 12) aponta que "essa estrutura agrária resulta do nosso passado colonial, esquematicamente constituído e organizado nos quadros do capitalismo internacional”. 
Portanto, essa característica está intimamente ligada à condição imperialista de país colonizado, sendo que sua relação com o centro capitalista referia-se apenas em abastecêlos de produtos agrícolas, o que lhe rendeu o reconhecimento secular de economia agroexportadora (PRADO JUNIOR, 1987).

Por sua vez, em 1850, o estado brasileiro (pós independência) cria a Lei de Terras, que revogava o sistema das sesmarias e estabelecia critérios para a organização e uso do solo no país. Essa lei foi uma solução encontrada pela elite brasileira para manter inalterada a estrutura agrária, impedindo o acesso à terra por parte da população pobre que era maioria e conseguir trabalhadores livres para trabalhar nas lavouras de café (MIRALHA, 2006, p. 153). Com isso, tal fato resultou na composição de uma complexa e histórica relação de classes no espaço rural, ao qual:

Os grandes proprietários e fazendeiros, lavradores embora, são antes de tudo homens de negócios para quem a utilização da terra constitui um negócio como outro qualquer. Do outro lado, para os trabalhadores rurais, para a massa camponesa de proprietários ou não, a terra e as atividades que nela se exercem constituem a única fonte de subsistência para eles acessível (PRADO JUNIOR, 1987, p. 22).

Além disso, conforme os relatórios do OXFAM/Brasil (2019, P. 02), "essa estrutura fundiária também é característica marcante na história de alguns países latinoamericanos, tanto que cerca de $1 \%$ das propriedades rurais, dessa região, são donas de $51 \%$ da área rural total". Além disso, a Colômbia é um dos exemplos mais emblemáticos, onde somente $0,4 \%$ das propriedades concentram mais de $67 \%$ das terras produtivas em todo o país. Enquanto no caso brasileiro, $45 \%$ da área rural estão nas mãos de menos de $1 \%$ dos grandes proprietários de terras (OXFAM/Brasil, 2019) (tabela 01).

Tabela 01: Concentração fundiária brasileira.

\begin{tabular}{c|c|c}
\hline $\begin{array}{c}\text { Grupos de área } \\
\text { (hectares) }\end{array}$ & $\begin{array}{c}\text { Estabelecimentos } \\
\text { agropecuários (\%) }\end{array}$ & $\begin{array}{c}\text { Concentração total da } \\
\text { área rural do país (\%) }\end{array}$ \\
\hline 2.500 & 0,3 & 30,4 \\
\hline $1.000-2.500$ & 0,6 & 14,6 \\
\hline $500-1.000$ & 01 & 11,16 \\
\hline $200-500$ & 2,9 & 13,9 \\
\hline $100-200$ & 4,2 & 8,7 \\
\hline $50-100$ & 7,5 & 7,9 \\
\hline $20-50$ & 16,3 & 3,0 \\
\hline $10-20$ & 14,2 &
\end{tabular}




\begin{tabular}{c|c|c}
\hline Até 10 & 47,8 & 2,3 \\
\hline Produtor sem área & 4,93 & - \\
\hline
\end{tabular}

Fonte: OXFAM/Brasil, 2019.

A concentração fundiária no Brasil reflete negativamente no incentivo ao desenvolvimento socioeconômico, pois ainda de acordo com a OXFAM/Brasil (2019, p.01) quando "as cidades foram comparadas em termos de IDH Municipal, verificou-se que os melhores indicadores sociais se apresentavam naqueles municípios com menor grau de concentração fundiária". Dessa forma, a organização territorial favoreceu os poucos estabelecimentos agropecuários que dominam grandes extensões de terras, onde na maioria dos casos não são utilizados para produzir, mas sim para especulação (os chamados latifúndios improdutivos) (tabela 01).

Sendo assim, formou-se no país uma elite agrária arcaica e parasitaria, porém fortemente organizada. Com poderes que vigoravam/vigoram não só na dimensão social, mas também econômica, política e religiosa. Outrossim, esses grupos concentram terras, rendas, empresas e compõe boa parte da bancada parlamentar brasileira. Vale dizer que essa configuração é marcante, sobretudo na região Nordeste, representando também as históricas oligarquias municipais.

Para tanto, a luta pelo acesso à justiça fundiária ganhou destaque, especialmente a partir da segunda metade do século XX. Onde, contraditoriamente, emergiram movimentos camponeses que reivindicavam a concretização do processo de reforma agrária, sendo, para Veiga (1981, p. 07), uma "reestruturação interna com vistas para distribuir equitativamente as terras e a renda agrícola". Nessa perspectiva, somente com as Ligas Camponesas, nas décadas de 1950 e 1960, e com o apoio do Partido Comunista Brasileiro (PCB), que a luta pela terra ganhou dimensão nacional (JESUS, 2011, p. 06)

Posteriormente, com o processo de redemocratização, o poder político foi reconstituído pelos ortodoxos liberais. Esses grupos defendiam um alinhamento direto com os interesses internacionais (especialmente dos Estados Unidos) e o estrangulamento do Estado. É tanto que a política de austeridade do governo de Fernando Collor de Mello retirou completamente da agenda pública o debate sobre a questão agrária e intensificou a repressão contra os movimentos sociais que lutavam pela terra (GOMES, 2013, p. 105). Todavia, foi nesse momento que a questão agrária ganhou um novo formato. Assim: 
Concebido pelos economistas do Banco Mundial, reconhecido na literatura como Modelo de Reforma Agrária de Mercado (MRAM), este modelo de uma diferença essencial quando comparado ao modelo tradicional (desapropriação de terras) que consiste na maneira de acesso a terra, realizada através do financiamento da compra da terra. A negociação é feita diretamente entre os beneficiários do MRAM e proprietários da terra. O valor acordado é pago a vista ao proprietário com recursos do Governo Federal e os beneficiários se responsabilizam pelo pagamento do financiamento correspondente (LIMA, 2011, p. 29).

Portanto, o MRAM interessou, principalmente, aos grandes latifundiários (improdutivos) na medida em que finalmente poderiam comercializar suas propriedades ao invés de cedê-las. A partir desse momento, o problema de distribuição da propriedade fundiária passa a ser uma questão financeira suscetível a evolução do mercado de valores e dependente, portanto, do que ocorra no mercado imobiliário, tanto para papeis públicos como privados (RANGEL, 2005, p. 74). Nesse ponto, Rangel (2005, p. 76) destaca ainda que "a estrutura agrária do país corresponde a essência das relações internas de produção (sob o caráter dual), da qual ocupa uma posição diametralmente oposta às das instituições que enquadram o comércio exterior”.

No entanto, na contramão do que vinha sendo feito pelo governo federal, algumas iniciativas regionais foram ganhando destaque. Uma delas foi o Projeto São José, criado no estado do Ceará, em 1996, que para Juvencio (2013, p. 28) significou a "viabilização do acesso a terra aos trabalhadores rurais sem-terra e minifundiários, a partir de uma abordagem inovadora e desburocratizada, sob a perspectiva do desenvolvimento sustentável local”. Posteriormente, surgiu o programa Banco da Terra, comprometendo-se em reduzir a pobreza rural, elevar a renda agrícola e implantar um modelo alternativo de reforma agrária desapropriacionista (MDA/CONTAG, 2016, p. 08). Então:

Esse programa atendeu um total de 35.372 mil famílias em uma área total de 1.141.341 ha. O montante total de recursos aplicados foi de 1.030.288.697,36, o que correspondente a uma média por família de $\mathrm{R} \$$ 29.127,24. Comparado esses valores com PTC pode-se observar um aumento médio da área adquirida em 8,8 ha por família, também aumentou o volume de recursos médios por família em $\mathrm{R} \$ 17.152,24$. Os Estados com maior adesão foram o Rio Grande do Sul e Santa Catarina, os quais beneficiaram, respectivamente, 10.241 famílias em a área de 119.331ha e 4.688 famílias em uma área de 75.482 ha (GOMES, 2013, p. 129). 
Diante disso, já em 2003 (num outro contexto político do país), o governo federal lança o II Plano Nacional de Reforma Agrária (II PNRA), durante a Conferência da Terra, em Brasília (MDA/CONTAG, 2016, p. 08). Com isso, Gomes (2013, p. 133) aponta que "nesse momento foi criado, mediante Secretaria de Reordenamento Agrário do MDA, o Programa Nacional de Crédito Fundiário (PNCF)". Tal projeto resultou da unificação dos demais projetos destacados anteriormente (Banco da Terra, Célula da Terra e o Projeto de Crédito Fundiário e Combate à Pobreza Rural- PCFCPR).

Para tanto, o PNCF é considerado um conjunto de ações que visa, por intermédio de crédito fundiário, a promoção do acesso a terra e a investimentos básicos e produtivos que permitam estruturar os imóveis rurais - de até 15 módulos -, adquiridos com recursos do Fundo de Terras e da Reforma Agrária, de modo a consolidar seu acesso a agricultura familiar (BRASIL, 2019). No entanto, embora seja reconhecido como uma ferramenta de reforma agrária de mercado, trata-se de uma política pública que apresenta características peculiares, como a descentralização e uma espacialização que alcança mais efetivamente os grupos de menor renda.

\section{CRÉdito FUNDIÁRIO E COMPLEXIDADE REGIONAL: BREVE ANÁLISE DO NORDESTE}

O programa, em sua originalidade, descentralizou parcialmente o processo de financiamento institucional e incorporou a participação de sindicatos e federações rurais, operando a partir de parcerias para fazer a intermediação entre os trabalhadores rurais e a política pública (WITTMANN, 2018, p. 21). Dos quais passaram a se responsabilizar-se pelo controle social dos recursos, avaliação documental dos interessados e orientação técnica dos projetos. Em Gomes (2013, p. 56), a descentralização "amplia a governança no sentido cívico, ou seja, aumenta a participação dos beneficiários, a regulação social dos fundos públicos e aos mecanismos de transparência e de responsabilização social”.

Outra característica do PNCF são as linhas de financiamento, de acordo com as necessidades de cada potencial beneficiário. Sendo elas: Consolidação da Agricultura Familiar (CAF), Combate à Pobreza Rural (CPR) e Nossa Primeira Terra (NPT). Onde a primeira é destinada a atender agricultores que já trabalham com a terra ou os que possuem pequenas propriedades e querem aumentar sua área, enquanto que a segunda visa auxiliar 
famílias rurais de baixa renda e a terceira trabalha, sobretudo, com o público jovem de 18 a 24 anos (tabela 02).

Tabela 02: Caracterização geral das linhas de financiamento do PNCF.

\begin{tabular}{|c|c|c|c|}
\hline $\begin{array}{l}\text { Linhas de } \\
\text { crédito }\end{array}$ & $\begin{array}{c}\text { Consolidação da } \\
\text { Agricultura } \\
\text { Familiar (CAF) }\end{array}$ & $\begin{array}{c}\text { Combate à } \\
\text { Pobreza Rural } \\
(\mathrm{CPR}) \\
\end{array}$ & $\begin{array}{c}\text { Nossa Primeira } \\
\text { Terra (NPT) }\end{array}$ \\
\hline Renda anual & Até R\$ 30 mil & Até R\$ 9 mil & Até R\$ $30 \mathrm{mil}$ \\
\hline Patrimônio & Até R\$ 60 mil & Até R\$ 30 mil & Até R\$ 60 mil \\
\hline Experiência & 5 anos & 5 anos & 5 anos \\
\hline Forma de acesso & Individual & $\begin{array}{l}\text { Coletivo e } \\
\text { individual }\end{array}$ & Individual \\
\hline Financiamento & Individual & Individual & Individual \\
\hline $\begin{array}{c}\text { Origem dos } \\
\text { recursos }\end{array}$ & $\begin{array}{c}\text { Subprojeto de } \\
\text { Aquisição de Terras } \\
\text { (SAT) e Subprojeto } \\
\text { de Investimento } \\
\text { (SIB) }\end{array}$ & $\begin{array}{c}\text { Subprojeto de } \\
\text { Aquisição de } \\
\text { Terras (SAT) e } \\
\text { Subprojeto de } \\
\text { Infraestrutura } \\
\text { Comunitário (SIC) }\end{array}$ & Reembolsável \\
\hline Taxa de juros & $2,0 \%$ & $0,5 \%$ & $1,0 \%$ \\
\hline
\end{tabular}

Fonte: CONTAG, 2008.

Vale dizer que com a autorização do Decreto $n^{\circ}$ 6.672/2008, que tornou o Combate à Pobreza Rural uma linha de financiamento do programa, o governo brasileiro passou a ter maior autonomia para gerir os recursos, dispensando inclusive o custeio do Banco Mundial, que ditava o regramento conforme critérios internacionais (CONTAG, 2016, p. 09). A partir de então, foi possível formalizar, em 2017, os subgrupos adicionais Juventude, Terra Negra e PNCF Mulher e categorizá-los conforme as necessidades e demandas de cada grupo social (WITTMANN, 2018, p. 22).

Sendo assim, além do financiamento do imóvel rural, as linhas oferecem recursos para investimentos comunitários nas propriedades, possibilitando aos agricultores um impulso essencial para o desenvolvimento de sua produção agropecuária e investimentos na moradia (IPEA, 2015, p. 13). Isso porque, segundo Leite (2000, p. 48), "os assentamentos tendem a promover um rearranjo do processo produtivo nas regiões onde se instalam, muitas vezes caracterizada por uma agricultura com baixo dinamismo". Com isso, tal financiamento pode inclusive chegar a $\mathrm{R} \$ 80 \mathrm{mil}$, de acordo com os tetos microrregionais, além de receber descontos de até $40 \%$ no valor da parcela para 
pagamentos efetuados dentro do vencimento (CEBDS, 2014, p. 43). Sendo assim, para adquirir o PNCF, é necessário:

Escolher bem a terra, negociar um preço acessível observando os valores das terras na região, e elaborar uma proposta de financiamento que já contemple o projeto produtivo e de estruturação da propriedade. Especialmente nessa fase inicial, é muito importante buscar o apoio de seu Sindicato ou da Federação de Trabalhadores e Trabalhadoras na Agricultura, que auxiliará na capacitação inicial, no acompanhamento da elaboração da proposta de financiamento e na negociação com o proprietário, garantindo projetos sustentáveis, diversificados e que visem à preservação ambiental e a organização das famílias (CONTAG, 2008, p. 09).

Vale dizer que os imóveis são escolhidos com base nas suas características de solo e localização, especialmente das sedes municipais, que servem de referência para o acesso a serviços básicos (saúde e educação) bem como a proximidade dos mercados (favorecer a comercialização) (SPAROVEK/MDA, 2005, p. 27). Além disso, a propriedade não pode ter pendências judiciais ou administrativas, assim como não pode está localizado em áreas de reservas indígenas, quilombolas e unidades de conservação ambiental.

Sendo assim, toda documentação deve ser avaliada pelo Conselho Municipal de Desenvolvimento Rural Sustentável (CMDRS) e pela Unidade Técnica Estadual (UTE). Após isso, será possível concluir o processo de compra e venda do imóvel, assim como integrar os beneficiários a demais políticas públicas de inclusão produtiva e desenvolvimento rural, como o Programa Nacional de Fortalecimento da Agricultura Familiar (PRONAF) e a Assistência Técnica de Extensão Rural (ATER) ${ }^{5}$.

Para tanto, em todo o país, foram efetivados mais de 63.000 (sessenta e três mil) contratos até o ano de 2017. Sendo o Nordeste, a região com maior índice de pequenos produtores ou famílias rurais que buscaram ter acesso ao programa nas diferentes linhas de financiamento (gráfico 01). Isso é importante do ponto de vista histórico, pois trata-se da região que apresenta os maiores desafios para desenvolver o mundo rural. Todavia, em termos estaduais, os que mais se destacaram foram o Rio Grande do Sul (região Sul), atendendo 27.492 famílias, seguido do Piauí e Maranhão.

\footnotetext{
${ }^{5}$ Em conformidade com a Resolução no 4.177/2013 do Conselho Monetário Nacional do Banco Central, do qual permite que as famílias atendidas pelo Cadastro Único tenham acesso ao financiamento com taxas de juros mais baixas que os demais beneficiários em melhores condições de renda.
} 
Gráfico 01: Famílias contratadas pelo PNCF por Unidade Federativa (UF)- região Nordeste.

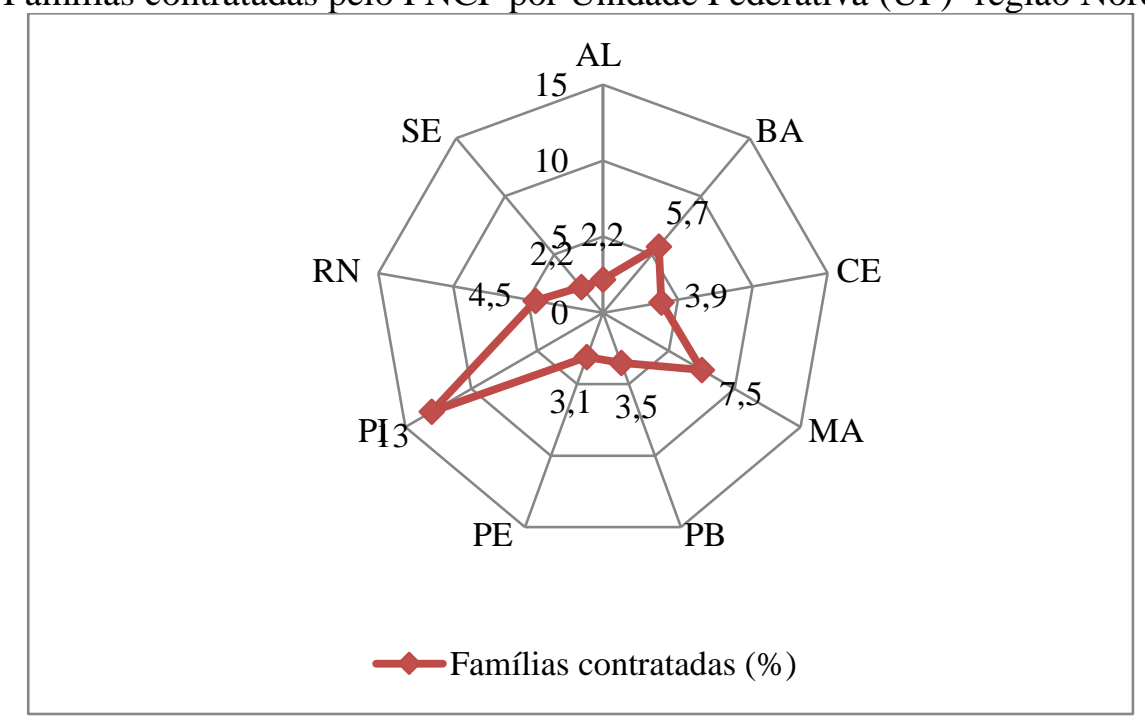

Fonte: Subsecretária de Reordenamento Agrário (SRA)/MDA, 2017.

Os reflexos do programa são ainda resultantes dos contrastes regionais, de acordo com as complexidades existentes em cada local. Essa profunda heterogeneidade socioeconômica e infraestrutural dos espaços é produto do grau de desenvolvimento das redes técnicas e da constituição de base material diferenciada, ao longo do tempo (SANTOS, 2006). Isso explica as distintas condições de acesso as propriedades, aos sindicatos (capilaridade social), tipos de financiamento, taxas de juros, entre outros. Portanto, o acesso ao PNCF pode apresentar assimetrias que não necessariamente estão ligadas a dimensão territorial de cada estado ou município (gráfico 01).

Para tanto, os entraves existentes no desenvolvimento do PNCF condicionam a redução de acesso aos novos beneficiários, assim como o aumento da inadimplência. Sendo assim, nos últimos anos têm-se debatido algumas propostas, no âmbito da Secretária de Reordenamento Agrário (SRA), como a criação de grupos de trabalho que visa discutir reestruturações do programa, considerando suas limitações e avanços, inclusive geográficos. Em vista disso, faz-se necessário realizar uma análise crítica que relacione as condições históricas, sociais, econômicas e, ainda, espaciais, com o grau de atuação do PNCF em cada região. 


\section{LIMITES E ALCANCE SOCIOECONÔMICO DO PNCF EM SERGIPE}

O crédito rural apresenta-se como um instrumento financeiro complementar de incremento a renda dos pequenos produtores. Ele ainda constitui o novo tripé de sustentação do desenvolvimento rural, baseado no enfoque territorial, juntamente com as políticas de comercialização e a assistência técnica (FAVARETO, 2006, p. 136). Até mesmo os mais pobres só conseguem se reproduzir fazendo algum tipo de poupança e procurando o tempo todo se garantir dos imprevistos, por isso, as finanças informais são a própria rede de relações sociais do qual dependem as famílias rurais (ABRAMOVAY, 2004, p. 21). Em vista disso, o PNCF, dentro dos seus limites e contradições, tem contribuído para implementar mudanças históricas e reais no meio rural brasileiro.

No caso de Sergipe, o programa é coordenado pela Empresa de Desenvolvimento Sustentável do Estado de Sergipe (PRONESE), funcionando como uma Unidade Técnica Estadual (UTE), que atua juntamente com o Conselho de Desenvolvimento Municipal (CONDEM) e o Conselho Estadual de Desenvolvimento Rural Sustentável (CEDRS), bem como demais entidades rurais. As negociações passam pela intermediação do governo estadual, depois disso, se aprovados, os recursos são repassados diretamente às comunidades e às famílias beneficiadas, por meio do Banco do Nordeste a título de financiamento (reembolsável) (RELATÓRIO DE ATIVIDADES DO GOVERNO DE SERGIPE, 2012, p. 82).

Desse modo, em termos quantitativos, nos últimos 16 anos (2003-2016) foram adquiridos em Sergipe cerca de 162 propriedades com tamanhos que variam entre $10 \mathrm{e}$ 1.200 hectares. Sendo os municípios de Lagarto e Porto da Folha, os mais beneficiados proporcionalmente. Portanto, o programa tem sido mais dinâmico nas regiões do alto sertão e centro sul do estado, das quais abrigam esses municípios (mapa 01). Destaca-se, com isso, o estabelecimento Fazenda Umbuzeiro, situado em Porto da Folha, como sendo a maior aquisição que Sergipe já fez no ano de 2008. 
Mapa 01: Municípios sergipanos beneficiados pelo PNCF (2003-2019).

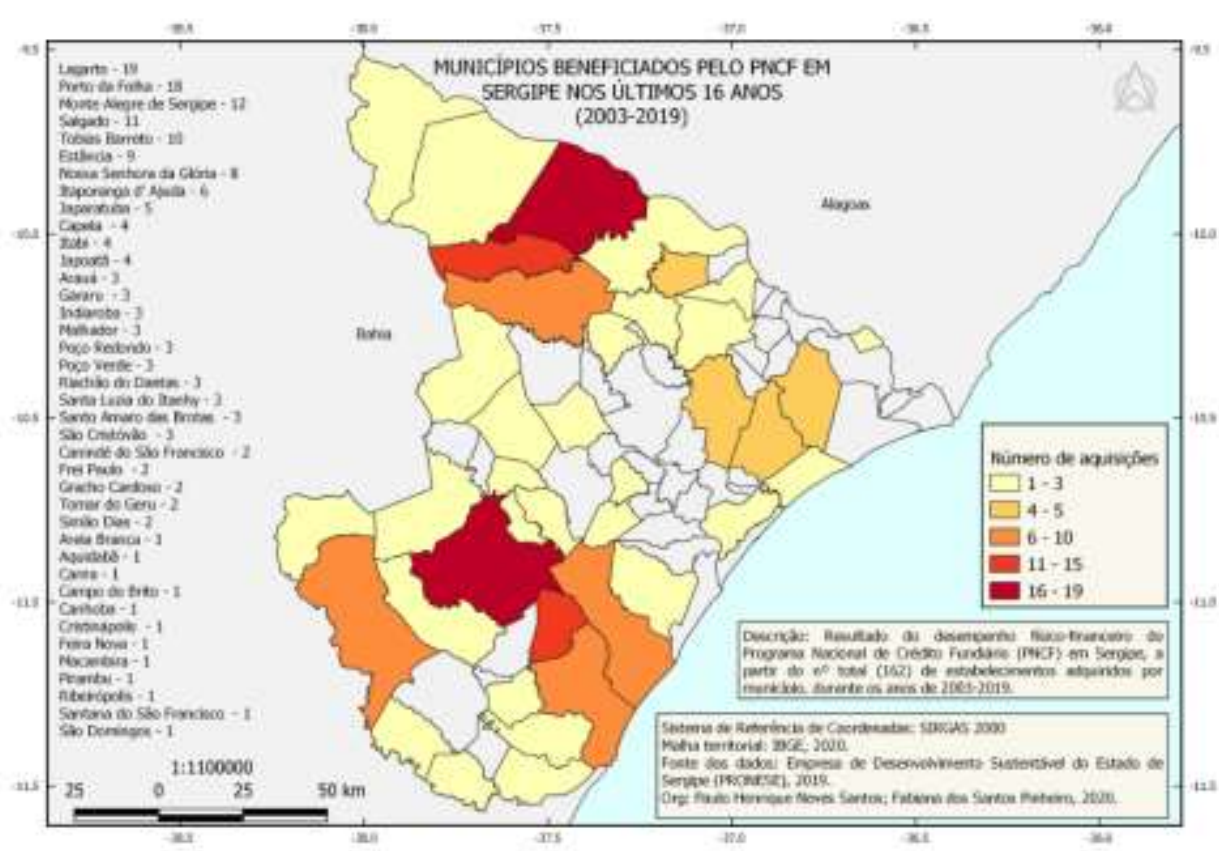

Fonte: PRONESE, 2019.

Elaboração: SANTOS e PINHEIRO, 2020.

Conforme demonstra o mapa acima, as cidades que mais se destacaram em número de aquisição dos estabelecimentos foram Lagarto, Porto da Folha, Monte Alegre de Sergipe e Salgado. Todavia, tal fato não foi regra, tanto que em Santo Amaro das Brotas, somente uma das propriedades adquiridas detinha 819,13 hectares de área, sendo um resultado muito mais expresivo se comparado com o índice médio (350 hectares) das aquisições em Porto da Folha. Assim sendo, os efeitos do PNCF nesses municípios, principalmente do alto sertão - que possui as maiores concentrações fundiárias do estado -, demonstram-se relevantes do ponto de vista da democratização do uso da terra.

Outra importante característica do PNCF em Sergipe é que a linha de financiamento Combate a Pobreza Rural (CPR) foi a que mais viabilizou crédito, seguido da Consolidação da Agricultura Familiar (CAF). Isso é relevante, pois ambas podem ser adquiridas de maneira individual (com exceção da segunda, da qual enquadra-se na modalidade individual e coletiva) e a taxa de retorno anualizada (juros) é formidavelmente mais viável para a realidade dos pequenos produtores rurais desses municípios.

Com isso, Sergipe foi um dos estados do Nordeste que, em 2009, mais beneficiou famílias rurais com o programa. Outro grande destaque do PNCF nesse território ocorreu 
em 2014 com a entrega de 07 (sete) propriedades numa área total de 1.139,75 hectares que beneficiaram diretamente 70 famílias em todo o território sergipano. Nos últimos anos, apesar da redução de novas negociações, o programa tem apresentado resultados importantes com a aquisição de novos estabelecimentos (tabela 03).

Tabela 03: Alguns resultados do PNCF em Sergipe.

\begin{tabular}{c|c|c|c|c|c|c}
\hline Imóvel & Ano & $\begin{array}{c}\text { Linha de } \\
\text { crédito }\end{array}$ & Município & Área (ha) & $\begin{array}{c}\mathbf{N}^{\mathbf{0}} \text { de } \\
\text { famílias }\end{array}$ & $\begin{array}{c}\text { Valores } \\
\text { (R\$) }\end{array}$ \\
\hline $\begin{array}{c}\text { Fazenda Barra } \\
\text { da Varginha }\end{array}$ & 2015 & CPR & $\begin{array}{c}\text { Porto da } \\
\text { Folha }\end{array}$ & 454,54 & 39 & $2.092 .423,32$ \\
\hline $\begin{array}{c}\text { Fazenda Santa } \\
\text { Maria }\end{array}$ & 2016 & CPR & Lagarto & 142,00 & 18 & $1.244 .177,93$ \\
\hline $\begin{array}{c}\text { Fazenda Cem } \\
\text { Passos }\end{array}$ & 2017 & CPR & Capela & 96,81 & 10 & $631.222,50$ \\
\hline $\begin{array}{c}\text { Fazenda } \\
\text { Lamarão }\end{array}$ & 2018 & CPR & Japaratuba & 209,19 & 13 & $754.388,76$ \\
\hline $\begin{array}{c}\text { Fazenda } \\
\text { Campo Alegre }\end{array}$ & 2019 & CPR & Gararu & 137,50 & 10 & $308.231,26$ \\
\hline
\end{tabular}

Fonte: PRONESE, 2019.

Por sua vez, no que se refere a um dos principais gargalos em Sergipe, destaca-se que além das quedas nas aquisições de novas propriedades, tem-se verificado que os poucos estabelecimentos aprovados possuem áreas (extensão) proporcionalmente menores, assim como o número de famílias beneficiadas vem regredindo progressivamente (tabela 03). Esta condição se deve aos reflexos da política de austeridade vivenciada nos últimos anos. Por conseguinte, o grande desafio é ampliar o alcance social desse programa com o objetivo de permitir o incentivo às aquisições conjuntas, bem como reconhecer as principais deficiências e obstáculos para ampliação da política pública.

Para tanto, uma enfática referência de alcance do programa em Sergipe é a propriedade Fazendinha, localizada na cidade de Lagarto (figura 01). Essa foi adotada como base empírica-analítica desse estudo, por apresentar dualmente grandes avanços, bem como gargalos significantemente preocupantes. Assim, trata-se de uma aquisição conjunta, da qual beneficiou diretamente 43 (quarenta e três) famílias rurais, sendo o maior assentamento de crédito fundiário desse município. Vale dizer que, a propriedade apresenta cerca de 35 tarefas por família, adquirida pelo valor de R \$3.469.499,78. Diante disso, o município de Lagarto chegou à marca de 19 propriedades obtidas pelo programa, totalizando R\$ 14.629.911,05 de investimentos (GOVERNO DE SERGIPE, 2019). 
Figura 01: Propriedade Fazendinha, localizada no povoado Jenipapo-Lagarto
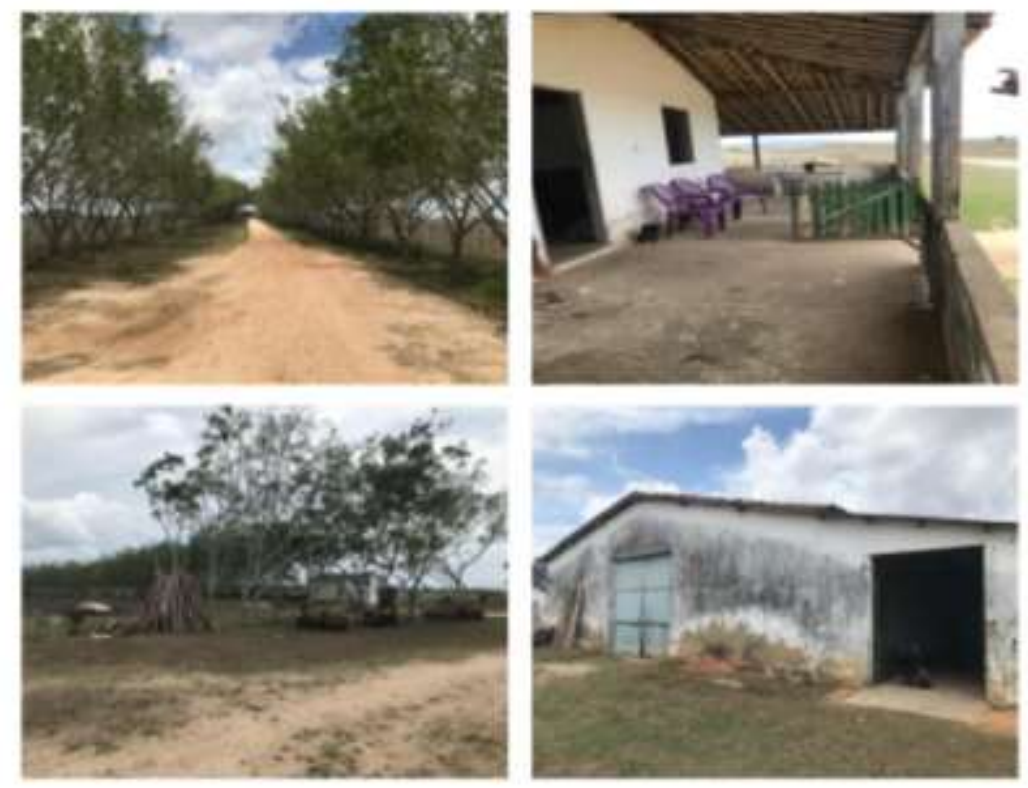

Fonte: Autores (trabalho de campo), 2021.

Durante a investigação in loco na referida propriedade, verificou-se que a estrutura da antiga fazenda encontra-se em situação precária, porém permanece ocupada por alguns dos assentados e serve ainda como sede temporária da associação local. Todavia, os entrevistados relataram que, por ser um estabelecimento recentemente adquirido, eles ainda aguardam a liberação dos recursos advindos das demais políticas públicas, como o PRONAF, para realizarem investimentos em seus lotes, a exemplo da construção de moradias e da construção de lavouras. Pretende-se, inclusive, plantar abóbora e abacaxi para a comercialização (assentado 01).

Nesse sentido, a base de reprodução das famílias locais é a renda proveniente do Bolsa Família, assim como os trabalhos diários em outras propriedades. Por sua vez, o pouco que se planta ainda é incipiente, pois as condições naturais, especialmente climáticas, não permitem que se produzam outras culturas. Apesar da carência de cinco anos para iniciar os pagamentos, esses assentados ainda não acessaram outros serviços básicos (energia, esgoto, água encanada, transporte, comunicação, etc.), nem tão pouco iniciaram os trabalhos com a terra para gerar renda e, assim, garantir os pagamentos. Nesse sentido, ver-se que a articulação entre as políticas públicas em Sergipe ainda é ineficiente.

Segundo o diretor regional do Sindicato dos Trabalhadores Rurais (SINTRAF) de Lagarto, essas famílias assentadas passam por inúmeras dificuldades que são específicas 
em cada propriedade. No caso desse município, ele destaca que não se fazem mais necessário novos recursos do PNCF, mas sim de uma reestruturação interna a partir daqueles assentamentos que apresentaram entraves e limitações. Pois problemas como a aquisições de terras a partir de beneficiários " laranjas", ou seja, firmamento de contratos por parte de pessoas que não tem direito ao programa - por ordem inclusive de fazendeiros locais - tem se tornado cada vez mais comum nos últimos anos. Além disso, transferências ilegais (venda ou aluguel) dos lotes tem chamado a atenção, isso em função das aquisições garantirem posteriores negociações.

Outro fato potencialmente crítico para a manutenção do PNCF na região centro sul do estado são as práticas de inadimplência intencional, onde muitos beneficiários que se comprometem com o programa, deixam de quitar as parcelas de maneira proposital (diretor do SINTRAF). Isso é ainda mais preocupante quando se trata das aquisições coletivas porque compromete todos os envolvidos. Ocorre que alguns assentados, depois de todo o processo de aquisição, acreditam que o não reembolso pode ser renegociável posteriormente, sobretudo, em feirões de perdão de dívidas, promovidos pelos bancos, por exemplo. Feliz engano, pois o que acontece é na verdade a perda do lote, do qual será levado a leilão pelo banco ou, até mesmo, a gestação de uma dívida ainda mais robusta que pode comprometer a renda futura do beneficiário.

Contudo, tais problemas têm alimentado demasiadas críticas ao programa. Tanto que para Silva (2013, p. 181) "a territorialização da RAM em Sergipe, foi produto de uma estratégia de contra-reforma agrária refuncionalizada". Todavia, ainda durante as visitas realizadas no SINTRAF, foi possível dialogar com outros assentados, dessa vez residentes do povoado Pururuca, que relataram suas experiências com o PNCF. Sendo estes profundamente satisfeitos com o programa, inclusive afirmando que tal política pública proporcionou a garantia de manutenção e a reprodução das famílias deste povoado. Por ser um assentamento mais antigo que o Fazendinha, na Pururuca os beneficiários já possuem acesso as redes de água (além das cisternas), energia e as moradias.

Em suma, as famílias dependem do que produzem e conseguem quitar anualmente as parcelas do financiamento (assentado 02). Portanto, o acesso ao crédito fundiário não deve ser visto tão somente como mecanismo de reprodução do capital, mas também como um complemento fundamental de mudanças reais das condições desses indivíduos e de 
suas respectivas famílias. Apesar disso, muitos ainda são incentivados, inclusive por grupos políticos locais, a não se comprometerem com os pagamentos e isso tem prejudicado ainda mais a atuação do programa.

Não obstante, a acessibilidade e o grau de atuação do programa de crédito fundiário no espaço rural de Sergipe, tem sido profundamente importante para as famílias rurais pobres, bem como tem refletido na permanência dessas pessoas no campo a na continuidade das atividades produtivas rurais. Por outro lado, problemas de caráter local tem tornado o programa consideravelmente contraditório e complexo. Portanto, faz-se necessário realizar uma avaliação periódica dos impactos do PNCF em cada região e discutir formas de superar os entraves que se apresentam nos seios dessas relações.

Para isso, devem-se entender os meios e os limites de integração das políticas públicas; verificar a distribuição de recursos por cada região de acordo com suas demandas e especificidades; avaliar os principais contrastes locais que levam as aquisições indevidas; entre tantas outras medidas. Em Sergipe, esse é um trabalho mais extenso e qualitativo que depende do apoio enérgico da PRONESE, da SEAGRI e do governo estadual para fiscalizar tais casos e repensar, juntamente com os sindicatos rurais, formas eficientes de melhorar esses condicionantes.

\section{CONSIDERAÇÕES FINAIS}

Historicamente, o Brasil é um dos países com maior índice de concentração fundiária do mundo. Isso está ligado ao seu passado colonial, bem como as estratégias de inviabilização de reforma agrária ao longo dos anos. Consequentemente, os anos 1980/90 marcaram um período de manutenção dos interesses internacionais, o que significava a não superação das desigualdades históricas do país. Nesse contexto, surge o PNCF (reforma agrária com caráter de mercado). Por sua vez, embora insuficiente e limitado, ao longo da sua trajetória o programa foi sofrendo mudanças, melhorias e adequações.

Atualmente, trata-se de um programa que visa atender a redução da desigualdade fundiária do Brasil. Portanto, sua territorialização na região Nordeste foi fundamental diante das demandas históricas pelo acesso a terra, o que tem refletido ainda, na melhoria das condições geográficas, no que se refere à distribuição das propriedades rurais. Além dele, demais programas de incentivo a inclusão produtiva e ao desenvolvimento rural 
foram trabalhados. Todavia, é preciso elencar que o PNCF é uma política de reforma agrária de mercado, portanto, não supera a dialética da desigualdade no campo, apesar de incrementar mudanças reais no atendimento de condições históricas.

Outro grande avanço a destacar é a democratização das instituições sociais (como os sindicatos) para o gerenciamento do programa. Sendo assim, o PNCF, dentro dos seus limites, tem contribuído para o desenvolvimento do mundo rural, juntamente com demais políticas públicas. Isso porque trata-se de um programa que apresenta um relevante alcance espacial e socioeconômico, devido as baixas taxas de juros oferecidas, possibilidade de linhas de crédito para cada grupo específico, financiamentos compatíveis com a renda de cada agricultor familiar, acesso a demais políticas públicas de inclusão produtiva e assistência técnica, entre outros. Dessa forma, sua ampliação é fundamental para garantir o fortalecimento e o fomento do desenvolvimento rural brasileiro.

No caso de Sergipe, o programa teve pouca adesão considerando demais estados do Nordeste, devido às condições gerais que cada estado teve para aderir o programa e adequá-los as realidades locais. Enquanto que no município de Lagarto sua dinâmica tem sido potencialmente específica, com avanços e problemas que precisam ser considerados periodicamente. Sendo o principal deles, e talvez o mais grave, o descomprometimento de alguns beneficiários com as aquisições. Onde utilizam do programa como um meio de comercialização ilegal dos lotes.

Apesar disso, o PNCF tem atendido regiões do estado com um alto grau de concentração fundiária e de pobreza rural. Refletindo ainda na capacidade produtiva e no aumento da renda dos agricultores familiares. Contudo, é preciso considerar que as possibilidades de acesso a terra tem sido realizadas de forma incoerente no Brasil, todavia, as políticas públicas que se apresentaram, especialmente a partir do século XXI, tem impactado no acesso a terra, aumento da renda e na redução da desigualdade fundiária no espaço rural deste país.

\section{REFERÊNCIAS}

ABRAMOVAY, Ricardo. Laços financeiros na luta contra a pobreza. São Paulo: Editora Annablume/FAPESP, 2004. 
BRASIL. Banco Central do Brasil (BCB). Resolução no 4.177 de 07 de janeiro de 2013: altera as normas para contratação das operações de crédito fundiário ao amparo do Fundo de Terras e da Reforma Agrária. Disponível em:

<https://www.bcb.gov.br/pre/normativos/res/2013/pdf/res_4177_v1_O.pdf>. Acesso em: 10 de janeiro de 2021.

BRASIL. Confederação Nacional dos Trabalhadores na Agricultura (CONTAG). PNCF: um jeito de conquistar a terra para viver e produzir com liberdade e dignidade. Brasília: SRA/FETAGs, 2008.

BRASIL. Conselho Empresarial Brasileiro para o Desenvolvimento Sustentável (CEBDS). Financiamento para pequenos e médios produtores rurais. Rio de Janeiro: Plataforma CEBDS, 2014.

BRASIL. Instituto de Pesquisas Econômica Aplicada (IPEA). Programa Nacional de Crédito Fundiário (PNCF): uma avaliação dos seus impactos regionais. Brasília: IPEA, 2015.

BRASIL. Ministério do Desenvolvimento Agrário (MDA). CONTAG e PNCF: uma experiência que vem transformando vidas no meio rural. Brasília: MDA/SRA, 2016. BRASIL. Ministério do Desenvolvimento Agrário (MDA). Estudos de Reordenamento Agrário: avaliação qualitativa do PNCF (2003-2010). Brasília: MDA/SRA, 2011. BRASIL. Organização Social OXFAM/Brasil. Menos de 1\% das propriedades agrícolas é dona de quase metade da área rural brasileira. Disponível em: $<$ https://oxfam.org.br/publicacao/menos-de-1-das-propriedades-agricolas-e-dona-dequase-metade-da-area-rural-brasileira/> . Acesso em: 26 de dezembro de 2019. BRASIL. Subsecretária de Reordenamento Agrário (SRA). Programa Nacional de Crédito Fundiário (PNCF). Disponível em: < https://www2.camara.leg.br/atividadelegislativa/comissoes/comissoes-permanentes/capadr/audiencias-publicas/audienciaspublicas-2017/audiencia-publica-16-de-maio-de-2017-casa-civil>. Acesso em: 29 de setembro de 2019.

FAVARETO, Arilson da S. Paradigmas do desenvolvimento rural em questão - do agrário ao territorial. Tese (Doutorado em Ciências Ambientais) - São Paulo: Universidade de São Paulo (USP), 2006. 
GOMES, Carla M. P. A governança da terra em questão: uma análise da política de crédito fundiário no Brasil. Dissertação (Mestrado em Ciências Agrárias) Florianópolis: Universidade Federal de Santa Catarina (UFSC), 2013.

JESUS, Alex D. Das Ligas ao MST: luta pela terra e a territorialidade camponesa. In: XIII Encuentro de Geógrafos de América Latina, 2011, San José. Anais do XIII EGAL, 2011.

JUVENCIO, Sara M. S. Terra de sonhos ou de mercados: avaliação do Projeto São José - ação fundiária, o caso do assentamento Floresta II, Quixadá-CE. Dissertação (Mestrado em Políticas Públicas) - Fortaleza: Universidade Federal do Ceará (UFC), 2013 .

LEITE, Sérgio. Impactos regionais da reforma agrária no Brasil: aspectos políticos, econômicos e sociais. In: LEITE, Pedro S. et al (Org.). Reforma agrária e desenvolvimento sustentável. Brasília, MDA, 2000, p. 37-54.

LIMA, Diego F. Avaliação de impacto do Programa Nacional de Crédito Fundiário na região sul do Brasil. Dissertação (Mestrado em Economia Aplicada) - Piracicaba: Escola Superior de Agricultura "Luiz de Queiroz”, 2011.

MARCONI, Marina de A.; LAKATOS, Eva M. Fundamentos de metodologia científica. $5^{\circ}$ ed. São Paulo: Editora Atlas, 2003.

MIRALHA, Wagner. Questão agrária brasileira: origem, necessidade e perspectivas de reforma hoje. Revista NERA - Presidente Prudente, ano 9, n. 8 - janeiro/junho de 2006. PRADO JUNIOR, Caio. A questão agrária. 4º ed. São Paulo: Editora Brasiliense, 1987. RANGEL, Ignacio. Obras reunidas (volume 2). In: O problema do preço da terra. Rio de Janeiro: Editora Contraponto, 2005.

VEIGA, José E. O que é reforma agrária. São Paulo: Editora Brasiliense, 1981. SANTOS, Milton. A natureza do espaço: técnica e tempo, razão e emoção. São Paulo: Editora Edusp, 2006.

SILVA, Nelmires F. da. Crédito fundiário e desenvolvimento territorial: entre o fetiche e o enfrentamento à questão agrária no alto sertão de Sergipe. Dissertação (Mestrado em Serviço Social). Recife: UFPE, 2013.

SERGIPE. Agência de Notícias de Sergipe (ANS). Trabalhadores Rurais recebem 43 títulos de terra do Programa de Crédito Fundiário no povoado Jenipapo. Disponível 
em:

<https://www.se.gov.br/noticias/Desenvolvimento/trabalhadores_rurais_recebem_43_titu los_de_terra_do_programa_de_credito_fundiario_no_povoado_jenipapo $>$. Acesso em: 29 de novembro de 2019.

SERGIPE. Empresa de Desenvolvimento Sustentável do Estado de Sergipe (PRONESE). Crédito Fundiário: desempenho físico-financeiro. 2019. Disponível em:

<https://www.pronese.se.gov.br/credito-fundiario-desempenho-fisico-financeiro>. Acesso em: 09 de dezembro de 2019.

SERGIPE. Governo de Sergipe. Relatório de atividades do governo: 2012. Sergipe, 2012. Disponível em: <https://www.sead.se.gov.br/wpcontent/uploads/2016/06/Relat\%C3\%B3rio-de-Atividades-2012.pdf>. Acesso em: 09 de dezembro de 2019.

SPAROVEK, Gerd (org.). Crédito fundiário e qualidade de vida no campo. Brasília: Estudos NEAD/MDA, 2005.

WITTMANN, Victor D. Programa Nacional de Crédito Fundiário (PNCF): perspectivas para a agricultura familiar no estado do Rio de Janeiro. Dissertação (Mestrado em Agricultura Orgânica) - Seropédica: UFRRJ, 2018. 